Although the end-point of the titration curve (Fig. 2) is not very sharp, it offers no explanation for this difference. It seems likely that the ammonia effect has to be explained by the difference in the electrode used. In our comparative studies on the determination of $-\mathrm{SH}$ groups in haemoglobins we therefore used a median ammonia concentration $(0.1 \mathrm{M})$ for both untreated and treated platinum-wire electrodes.

An important finding is the effect of the pretreatment of the platinum electrode with ammoniacal mercuric chloride solution before use. The final results obtained with such a system for studying native human haemoglobin are in agreement with the data obtained by Ingram (1957), except that only one end-point was found in our experiments. The differences between the results in titrations with the untreated platinum electrode and with the mercury-coated electrode must be explained rather by the different experimental conditions than by a different reactivity of some of the sulphydryl groups in the haemoglobin, as examination of the current-voltage curves has shown an increased sensitivity of the mercury-coated electrode. Moreover, the results of repeated titrations with a mercury-coated platinum electrode show a gradual decrease in the amount of silver bound. We therefore believe that the number of reactive -SH groups of different haemoglobins, and perhaps of other proteins, can be studied in the native state and after denaturation very clearly by the procedure using a mercury-conted platinum-wire electrode.

\section{SUMMARY}

1. A detailed description of the argentometrictitration procedure with a rotating mercurycoated platinum electrode for the estimation of the number of reactive sulphydryl groups in normal adult human haemoglobin is given.

2. A comparison of this method with the technique using an untreated platinum electrode revealed that with the latter procedure lower amounts of titratable-SH groups were found to be present in native adult human haemoglobin. It is suggested that this decrease is caused by the different experimental conditions.

3. The titration curves obtained by amperometric titration of native normal adult human haemoglobin with silver nitrate at the mercurytreated platinum electrode show only one sharp end-point.

\section{REFERENCES}

Benesch, R. E., Lardy, H. A. \& Benesch, R. (1955). J. biol. Chem. 216, 663.

Hommes, F. A., Dozy, A. \& Huisman, T. H. J. (1958). Biochem. J. 68, 309.

Hommes, F. A., Santema-Drinkwaard, J. \& Huisman, T. H. J. (1956). Biochim. biophys. Acta, 20, 564.

Huisman, T. H. J. \& Schreuder, J. (1957). Clin. Chim. Acta, 2, 210.

Ingbar, S. H. \& Kass, E. H. (1951). Proc. Soc. exp. Biol., N.Y., 77, 74.

Ingram, V. M. (1955). Biochem. J. 59, 653.

Ingram, V. M. (1957). Biochem. J. 65, 760.

van der Schaaf, P. C. \& Huisman, T. H. J. (1955). Biochim. biophys. Acta, 17, 8.

\title{
The Determination of Phylloerythrin in Blood
}

\author{
BY D. D. PERRIN* \\ Ruakura Animal Research Station, Hamilton, Department of Agriculture, New Zealand
}

(Received 21 May 1957)

Diseases of livestock in which there is an acute sensitivity of exposed parts to sunlight occur in many parts of the world. The need to identify the photodynamic agents responsible has been stressed (Clare, 1952). Photosensitivity directly due to components of the diet has been shown to occur in some instances, such as in poisoning by plants of the genus Hypericum (Pace, 1942), by Fagopyrum esculentum (Wender, Gortner \& Inman, 1943), and after administration of phenothiazine to calves (Clare, 1947) and lambs (Gordon \& Green, 1951).

* Present address: The John Curtin School of Medical Research, The Australian National University, Canberra, Australia.
More commonly, where liver damage is also found, the pigment phylloerythrin may be responsible (Clare, 1952). Phylloerythrin has been shown conclusively to be the photodynamic agent in geeldikkop (Rimington \& Quin, 1934), in facial eczema (Clare, 1944), in congenital photosensitivity in Southdown sheep (Clare, 1945), in bile-duct ligation in sheep (Rimington \& Quin, 1934) and in poisoning of sheep by Lippia rehmanni, Panicum miliaceum, Myoporum laetum and copper (Clare, 1952).

Phylloerythrin, a normal component of the bile and faeces of herbivores, is formed by microbial degradation of chlorophyll and related pigments in 
their passage through the gut (Quin, Rimington \& Roets, 1935), from which it is partially absorbed and re-excreted into the bile. In certain types of liver dysfunction, phylloerythrin accumulates in the peripheral circulation, causing intense photosensitization.

In photosensitivity diseases where the photodynamic agent is unknown it is desirable to examine affected animals for phylloerythrinaemia, but no quantitative method for the estimation of phylloerythrin in blood or urine has previously been described.

To provide information on levels of blood phylloerythrin in photosensitive animals, and as part of an investigation of sporadic photosensitization in sheep and cattle, a method has been developed for the estimation of phylloerythrin in small blood samples. This method depends on the measurement of the light absorption of phylloerythrin in ether at one or other of the peaks in the banded absorption spectrum in the visible and the near ultraviolet.

The procedure described in this paper is based on Fischer's (1926) method of porphyrin extraction from blood serum, modified slightly to obtain a more granular protein precipitate. The number of extractions, volumes and concentrations specified was selected to minimize interference by protoporphyrin without undue loss of phylloerythrin, and were checked with normal sheep plasma to which had been added known amounts of phylloerythrin and protoporphyrin.

\section{EXPERIMENTAL}

Spectrophotometry. All measurements were made on a Beckman model DU photoelectric quartz spectrophotometer checked frequently for wavelength calibration against the more intense lines of a mercury arc between 2225 and $5791 \AA$. For phylloerythrin estimations the slit width was set at $0.03 \mathrm{~mm}$. (band width $7 \AA$ at $4200 \AA$ ). The microcells (Pyrocell Manufacturing Co., U.S.A.) had a minimum volume of $100 \mathrm{~mm} .^{3}$ and a light path of $1 \mathrm{~cm}$.

Reagents. All reagents except ethyl ether were A.R. grade. Ether was laboratory-reagent grade purified by shaking with acid $\mathrm{FeSO}_{4}$ solution and redistilling.

Pure phylloerythrin was prepared from dried ox bile by the method of Rimington \& Quin (1934). The ether extract was washed with $2 \%(\mathrm{w} / \mathrm{v}) \mathrm{HCl}$ during repeated transferences between ether and $10 \%(w / v) \mathrm{HCl}$. The $10 \% \mathrm{HCl}$ solution was extracted with chloroform, which was washed with water, dried and evaporated in air. The dried material was taken up in a small volume of pyridine and the cycle repeated several times. After two such cycles no changes were observed in the number and positions of the absorption maxima or in their relative intensity. The final chloroform extract was slowly evaporated, yielding a crystalline material that was used without further purification. The visible absorption maxima in ether $(519 \cdot 5,560 \cdot 0$, $584.0,638.0 \mathrm{~m} \mu$ ) are in reasonable agreement with earlier data for phylloerythrin in this solvent [e.g. Hellström
(1931): 512.3-526・6, 558・0, 579・8, 595・0, 635.2 $\mathrm{m} \mu$; Fischer (1933): 521, 561, 584, 593, $637 \mathrm{~m} \mu$; Keys \& Brugsch (1938): $521,559,588,637 \mathrm{~m} \mu$; Clare (1944): 522, 561, 585-597, $636 \mathrm{~m} \mu$ ]. These maxima and the ratios of their intensities $(1.0,1.52,1.03,0.220$ respectively) agree closely with values obtained for phylloerythrin in dioxan by Stern \& Wenderlein $(1935)(517 \cdot 5,557 \cdot 5,581 \cdot 5,634 \mathrm{~m} \mu$; intensities $1 \cdot 0,1 \cdot 52,1 \cdot 00,0 \cdot 218)$ and Lemberg \& Falk (1951) (519, $559,583.5,637.5 \mathrm{~m} \mu$; intensities $1.0,1 \cdot 47,0.98,0.224)$.

Protoporphyrin was prepared from haemoglobin by the method of Keys \& Brugsch (1938) and purified by repeated distribution between ethyl ether and aq. $\mathrm{HCl}$ solutions. Absorption maxima in ether-acetic acid were at 5030 , 5365,5780 and $6320 \AA$, in good agreement with the values of $5020,5370,5760$ and $6325 \AA$ given by Lemberg \& Legge $(1949 a)$. The concentration of protoporphyrin in the final ether solution was determined by the method of Grinstein \& Wintrobe (1948).

Procedure. Serum or plasma $(10 \mathrm{ml}$.) was shaken with ethyl ether $(20 \mathrm{ml}$.$) , followed by the addition of ether-$ acetic acid $(1: 1 ; 30 \mathrm{ml}$.). The flask was stoppered, shaken and left for $30 \mathrm{~min}$. The ether layer was decanted into a separating funnel and the residue washed with ether $(3 \times 10 \mathrm{ml}$.), which was allowed to stand in contact for several minutes before decanting. The combined extracts were shaken with $2 \%(\mathrm{w} / \mathrm{v}, 0.55 \mathrm{M}) \mathrm{HCl}(3 \times 20 \mathrm{ml}$.). The combined $\mathrm{HCl}$ washings were extracted with ether $(2 \times 5 \mathrm{ml}$.), the ether layers being transferred by teat pipette to the original ether extract, which was then shaken with $20 \%(\mathrm{w} / \mathrm{v}, 6 \mathrm{~m}) \mathrm{HCl}(3 \times 4 \mathrm{ml}$.). The combined $20 \%$ $\mathrm{HCl}$ extracts were centrifuged to ensure separation of any ether emulsion and washed with ethyl ether (1-2 ml.) to remove traces of ether-soluble pigments. Ether $(2 \mathrm{ml}$.) was added before shaking with alkaline sodium acetate $(25 \mathrm{ml}$. of $0.9 \mathrm{M}$-sodium acetate; $1.5 \mathrm{M}$ in $\mathrm{NaOH}$ ), followed by further extraction with ether $(3 \times 3 \mathrm{ml}$.). This amount of alkaline sodium acetate left the aqueous phase slightly acid and thereby reduced further the risk of contamination by porphyrins of lower acid number. The ether extracts were mixed in a stoppered graduated cylinder and the volume was noted.

The optical density of the ether solution was measured with stoppered $2 \mathrm{~cm}$. cells at 4120, 4140, 4170, 4230, 4290 and $4700 \AA$, against water. The phylloerythrin concentration in the original plasma was obtained from the relation

$$
c(\mathrm{mg} . / 100 \mathrm{ml} .)=0.020 \mathrm{~V}\left(E_{4140}-E_{4700}\right) \text {, }
$$

where $V$ is the final volume of ether. The factor 0.020 includes a correction for the recovery of only $87 \%$ of phylloerythrin (see below).

The reliability of the determination was checked:

(i) by comparing $\left(E_{4170}-E_{4230}\right)-\left(E_{4230}-E_{4290}\right)$ with $\left(E_{4140}-E_{4700}\right)$. The ratio, $R$, of these quantities should be close to $0 \cdot 23$;

(ii) by confirming that $E_{4140}$ was greater than $E_{4120}$ and $E_{4170}$.

For more dilute solutions approximate values can be obtained by extracting the final ether solution into $20 \%$ $\mathrm{HCl}(1 \mathrm{ml}$.$) and driving any phylloerythrin back into a$ small volume of ether with alkaline sodium acetate $(2 \mathrm{ml}$.).

Higher concentrations can be measured with shorter absorption cells, dilution of the ether extract or absorption measurements in the visible. Beer's Law is obeyed at the four visible maxima for concentrations of phylloerythrin in 
ether up to at least $3.5 \mathrm{mg} . / 100 \mathrm{ml}$, and the ratios of the optical densities at the maxima provide a purity check. The phylloerythrin in the original plasma is given by

$$
c(\mathrm{mg} . / 100 \mathrm{ml} .)=0.23 V E_{5600} \text {. }
$$

\section{RESULTS}

\section{Absorption spectrum of phylloerythrin}

Fig. 1 shows the absorption spectrum of phylloerythrin in ethyl ether saturated with aq. acetic acid under the conditions described above for the estimation of phylloerythrin. Observed maxima, minima and extinction coefficients are given in Table 1.

The shape of the absorption curve and the positions of the maxima were unchanged when the ether extract was washed with water and with $2 \%$ $\mathrm{HCl}$.

The inflexion at $4260 \AA$, which is absent from the spectral-absorption curves for most porphyrins, including protoporphyrin, mesoporphyrin and coproporphyrin, provides a convenient check on the purity of solutions prepared for phylloerythrin estimation. Over the successive and equal wavelength intervals $4170-4230,4230-4290 \AA$, there is a considerable difference in the optical-density increments (Fig. 2). This difference

$$
\left[d=\left(E_{4170}-E_{4230}\right)-\left(E_{4230}-E_{4290}\right)\right]
$$

is a constant fraction of the optical densities at any selected wavelengths, e.g. 4140 and $4700 \AA$. This follows directly from Beer's Law $(E=\epsilon c t)$, which holds for all wavelengths. Thus

and

$$
d=\left[\left(\epsilon_{4170}-\epsilon_{4230}\right)-\left(\epsilon_{4230}-\epsilon_{4290}\right)\right] c t,
$$

Hence

$$
\begin{aligned}
d & =\frac{\left(\epsilon_{4170}-\epsilon_{4230}\right)-\left(\epsilon_{4230}-\epsilon_{4290}\right)}{\left(\epsilon_{4140}-\epsilon_{4700}\right)}\left(E_{4140}-E_{4700}\right) \\
& =R\left(E_{4140}-E_{4700}\right),
\end{aligned}
$$

where $R$ is a constant.

For phylloerythrin in ether $R$ has a value of $0 \cdot 23$. The inflexion is absent from solutions of phylloerythrin in aqueous hydrochloric acid. Although the inflexion is also absent from solutions of protoporphyrin in ether the absorption spectrum of this pigment shows sufficient curvature between 4170 and $4290 \AA$ to give a value of $R=0 \cdot 10$.

\section{Sensitivity}

The method as described enables plasma phylloerythrin levels to be determined over the range $0.05-0.5 \mathrm{mg} . / 100 \mathrm{ml}$. The use of visible absorptionspectrum measurements for high plasma phylloerythrin concentrations extends this range to

\begin{tabular}{|c|c|c|}
\hline Maxima (§) & Minima (§) & $E_{1 \% \mathrm{~m}}^{1 \%}$. \\
\hline $\begin{array}{c}4140 \\
4260 \\
\text { (inflexion) }\end{array}$ & - & $\begin{array}{l}2800 \\
1560\end{array}$ \\
\hline- & $\begin{array}{c}4760 \\
\text { (very flat) }\end{array}$ & 50 \\
\hline 5195 & - & 159 \\
\hline & 5420 & 82 \\
\hline 5600 & - & 242 \\
\hline- & 5735 & 99 \\
\hline 5840 & - & 163 \\
\hline$\overline{6280}$ & 6215 & $13 \cdot 3$ \\
\hline 6380 & - & 35 \\
\hline
\end{tabular}

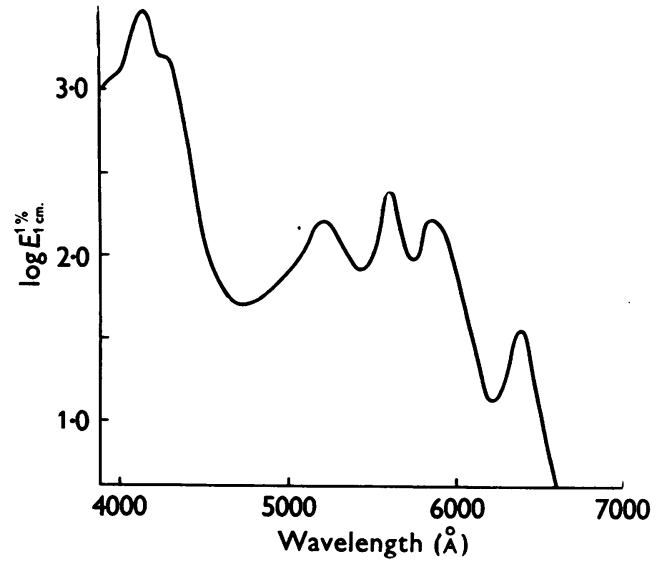

Fig. 1. Absorption spectrum of phylloerythrin in ethyl ether saturated with aq. acetic acid.

Table 1. Phylloerythrin in ether-acetic acid

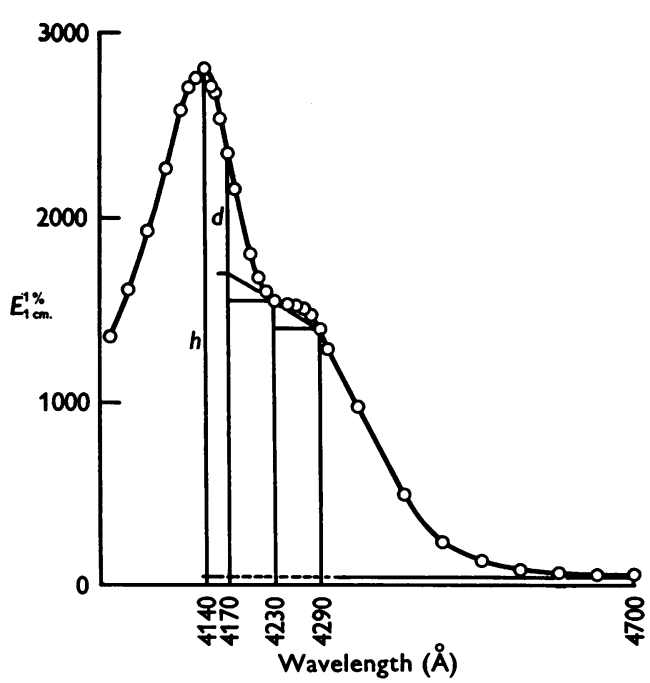

Fig. 2. Use of inflexion in absorption spectrum of phylloerythrin in ether saturated with aq. acetic acid as purity check. The ratio $d: h(0 \cdot 23)$ is independent of concentration. 
$3.5 \mathrm{mg} . / 100 \mathrm{ml}$. By the use of microcells and application of the $R$ test in the modified method for very low levels of phylloerythrin a limit of detection of the order of $0.005 \mathrm{mg} . / 100 \mathrm{ml}$. is given.

\section{Specificity}

The wavelength of the Soret maximum provides a useful qualitative check on the pigment obtained in the method described. Thus phylloerythrin in ether has $\lambda_{\max .}=4140 \AA$; protoporphyrin, $\lambda_{\max .}=$ $4040 \AA$. Owing to the sharpness of the Soret band and the rapid rate of change of optical density with wavelength near the maximum, the position of the maximum is relatively little affected by the presence in the solution of compounds such as bilirubin, which show a more general light-absorption. For this reason an independent check on the purity of the ether extracts is necessary and this is provided, quantitatively, by calculation of $R$.

The hydrochloric acid number of protoporphyrin [2.0, Keys \& Brugsch (1938)] is close enough to that of phylloerythrin [8.5, Keys \& Brugsch (1938)] for significant amounts to be carried through. In human red-blood cells normal protoporphyrin levels are less than $0.05 \mathrm{mg} . / 100 \mathrm{ml}$. (Cartwright, Lauritsen, Jones, Merrill \& Wintrobe, 1946); in sheep the values are 0.03-0.09 (Allen, 1956). Kench, Gillam \& Lane (1942) found whole-blood protoporphyrin concentrations up to $0.4 \mathrm{mg}$./ $100 \mathrm{ml}$. in human chronic lead-poisoning cases and reported that in this condition generally protoporphyrin concentrations were higher in plasma than in red cells. Values up to $1 \mathrm{mg}$. $/ 100 \mathrm{ml}$. of red blood cells have been reported (Dr E. C. Vigliani, quoted by Lemberg \& Legge, 1949b). Recovery experiments with protoporphyrin added to plasma showed that a plasma protoporphyrin concentration of $1 \mathrm{mg} . / 100 \mathrm{ml}$. gave an apparent phylloerythrin value of $0.04 \mathrm{mg} . / 100 \mathrm{ml}$. This was shown to be spurious when $R$ was found to be 0.10 and not $\mathbf{0 . 2 3}$ as required for phylloerythrin. Concentrations of protoporphyrin high enough to cause significant interference are unlikely to be encountered in practice.

Deutero-, meso-, haemato- and copro-porphyrins, which are known or believed to occur in normal or pathological metabolism, have much lower hydrochloric acid numbers (Keys \& Brugsch, 1938), and present no difficulty in obtaining quantitative separation from phylloerythrin. Uroporphyrin is insoluble in ether acidified with acetic acid.

Bilirubin, biliverdin and carotene (which is a normal constituent of bovine plasma) are quantitatively rejected in the extraction process described. Haemolysis of the sample does not affect the determination.

The possible effects of chlorophyll-degradation products other than phylloerythrin have not been investigated experimentally. However, Rothemund (1935), in his examination of ox bile for porphyrins derived from chlorophyll, found only phylloerythrin and smaller quantities of pyrroporphyrin, and no phylloporphyrin or rhodoporphyrin. Pyrroporphyrin, with an acid number of $\mathbf{1 . 5}$, is unlikely to interfere in the estimation of phylloerythrin by the method described.

Recoveries. The extraction process entails some loss of phylloerythrin because of the necessity to remove most of the protoporphyrin, the greatest loss occurring during the washing with $2 \%$ hydrochloric acid. The extent of the overall loss was determined by recovery experiments. Recoveries of phylloerythrin in ether added to plasma, within the range $0.06-1.37 \mathrm{mg} . / 100 \mathrm{ml}$., followed by evaporation of the ether, amounted to $87 \pm 6 \%$ (range 80-96). On the basis of these results, multiplication by 1.15 is included in the factor used to convert optical densities into plasma phylloerythrin concentrations.

Below about $0.05 \mathrm{mg}$. $/ 100 \mathrm{ml}$. differences are not sufficiently great for accurate calculation of $R$ and hence there is no reliable check on the apparent phylloerythrin values obtained. In a series of experiments with plasma to which had been added $0.007-0.032 \mathrm{mg}$. of phylloerythrin $/ 100 \mathrm{ml}$., recoveries were $0.012-0.054 \mathrm{mg} . / 100 \mathrm{ml}$., including a (spurious) plasma blank of $0.004 \mathrm{mg} . / 100 \mathrm{ml}$. In a typical experiment an ether extract with an apparent phylloerythrin content of $0.015 \mathrm{mg} . /$ $100 \mathrm{ml}$. was concentrated into $0.5 \mathrm{ml}$. of ether. Measurement by microcell (slit width $0.06 \mathrm{~mm}$.) gave the original phylloerythrin level as $0.007 \mathrm{mg}$./ $100 \mathrm{ml}$., $R=0 \cdot 19$.

\section{DISCUSSION}

In their work on geeldikkop, Rimington \& Quin (1934) isolated phylloerythrin from large volumes of blood from affected sheep but did not determine its concentration. Clare (1944), using existing methods of porphyrin extraction and various modifications, followed by fluorimetric estimation, was unable to obtain even roughly quantitative recoveries of phylloerythrin added to blood, and in some of his experimental sheep photosenisitization after injection of phylloerythrin occurred when peripheralblood phylloerythrin had fallen below levels he could detect. Clare concluded that if, in affected sheep, the pigment was found in the blood sufficient was present to cause photosensitivity.

The present method enables phylloerythrin in low concentrations in blood to be identified and estimated. The use of an internal spectroscopic check which depends on the shape of the phylloerythrin-absorption curve considerably increases the reliability of the determination. The sharpness 
of the phylloerythrin absorption bands and the dependence of $R$ on small wavelength differences require accurate calibration of the spectrophotometer and the use of narrow slit widths.

The highest plasma phylloerythrin level so far found with the method described has been $0.3 \mathrm{mg}$./ $100 \mathrm{ml}$., in a sheep poisoned by Panicum miliaceum, although Clare (1944) estimates that levels up to at least $1.6 \mathrm{mg}$. $/ 100 \mathrm{ml}$. occur in severe cases of facial eczema in sheep.

The method appears to be applicable to other biological materials, especially urine. Phylloerythrin has been detected in the urine of humans on vegetable diets (Kemeri, 1924; Fischer \& Hilmer, 1925), indicating that absorption of chlorophylldegradation products from the gut can take place in humans. Whether phylloerythrinaemia occurs in human-liver dysfunctions and porphyrias is not at present known, but the method described makes feasible the examination of blood from affected persons. In addition to its application to photosensitivities of unknown origin it also enables information to be obtained on the concentrations of phylloerythrin involved in photosensitization in sheep and cattle.

\section{SUMMARY}

1. Details are given of a method for estimating phylloerythrin in blood, consisting in extraction into ether-acetic acid solution, distribution between ether and hydrochloric acid solutions, and spectrophotometric measurement.

2. The inflexion at $4260 \AA$ in the absorption spectrum of phylloerythrin provides a quantitative check on the purity of the material being measured.

3. The method is applicable over the range $0.05-3.5 \mathrm{mg}$. of phylloerythrin $/ 100 \mathrm{ml}$. of plasma, but a modification giving approximate values down to $0.005 \mathrm{mg}$. $/ 100 \mathrm{ml}$. is described. Protoporphyrin and other porphyrins do not cause significant interference.

\section{REFERENCES}

Allen, S. H. (1956). Biochem. J. 63, 461.

Cartwright, G. E., Lauritsen, M. A., Jones, P. J., Merrill, I. M. \& Wintrobe, M. M. (1946). J. clin. Invest. 25, 65. Clare, N. T. (1944). N.Z. J. Sci. Tech. A 25, 202.

Clare, N. T. (1945). N.Z. J. Sci. Tech. A 27, 23.

Clare, N. T. (1947). Aust. vet. J. 23, 340.

Clare, N. T. (1952). Photosensitization in Diseases of Domestic Animals. Farnham Royal, Bucks: Commonwealth Agricultural Bureau.

Fischer, H. (1926). Neuere Methoden der Isolierung und des Nachweises von Porphyrinen. In Abderhalden's Handbuch der biologischen Arbeitsmethoden. Berlin: Urban and Schwarzenburg.

Fischer, H. (1933). Oppenheimer's Handbuch der Biochemie, 2nd ed., suppl. vol. 1 (1), pp. 247 et seq. Jena: G. Fischer. Fischer, H. \& Hilmer, H. (1925). Hoppe-Seyl. Z. 143, 1.

Gordon, H. M. \& Green, R. J. (1951). Aust. vet. J. 27, 51.

Grinstein, M. \& Wintrobe, M. M. (1948). J. biol. Chem. 172, 459.

Hellström, H. (1931). Z. phys. Chem. $14 \mathrm{~B}, 9$.

Kemeri, D. (1924). Biochem. Z. 151, 446.

Kench, J. E., Gillam, A. E.\& Lane, R. E.(1942). Biochem. J. 36, 384.

Keys, A. \& Brugsch, J. (1938). J. Amer. chem. Soc. 60, 2135.

Lemberg, R. \& Falk, J. E. (1951). Biochem. J. 49, 674.

Lemberg, R. \& Legge, J. W. (1949a). Haematin Compounds and Bile Pigments, p. 74. New York: Interscience.

Lemberg, R. \& Legge, J. W. (1949b). Haematin Compounds and Bile Pigments, p. 580. New York: Interscience.

Pace, N. (1942). Amer. J. Physiol. 136, 650.

Quin, J. I., Rimington, C. \& Roets, C. G. S. (1935). Onderstepoort J. vet. Sci. 4, 463.

Rimington, C. \& Quin, J. I. (1934). Onderstepoort J. vet. Sci. 3, 137.

Rothemund, P. (1935). J. Amer. chem. Soc. 57, 2179.

Stern, A. \& Wenderlein, H. (1935). Z. phys. Chem. A 174, 81.

Wender, S. H., Gortner, R. A. \& Inman, O. L. (1943). J. Amer. chem. Soc. 65, 1733.

\title{
APPENDIX
}

\section{The Form in which Phylloerythrin Occurs in Bile and Blood}

\author{
BY D. D. PERRIN \\ Ruakura Animal Research Station, Hamilton, Department of Agriculture, New Zealand
}

(Received 21 May 1957)

Although phylloerythrin is extremely insoluble in water it occurs as a normal constituent of sheep and ox bile, from which it is not thrown down on centrifuging. Similarly, although it can be quantitatively extracted into ether from bile acidified with acetic acid, phylloerythrin is not readily extracted from fresh bile with ether alone. A similar observation was made with plasma from a congenitally photosensitive Southdown sheep. Dialysis of bile in collodion tubes led to the deposition of most of the phylloerythrin on the walls, with very little present in the diffusate. The effect of $\mathrm{pH}$ on 